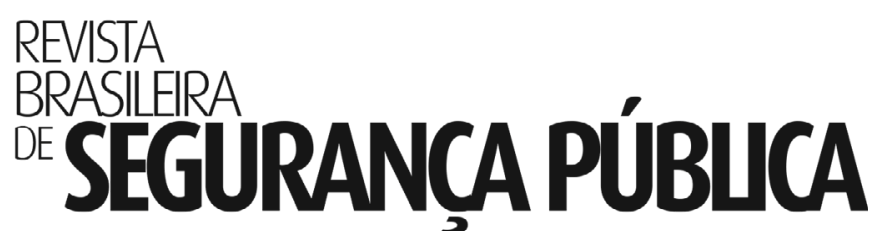

\author{
Volume 12 \\ Número 2 \\ Agosto/Setembro de 2018
}

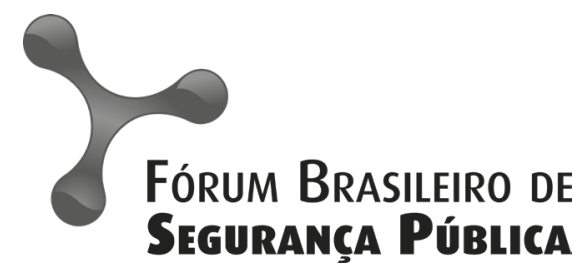

ISSN 1981-1659 


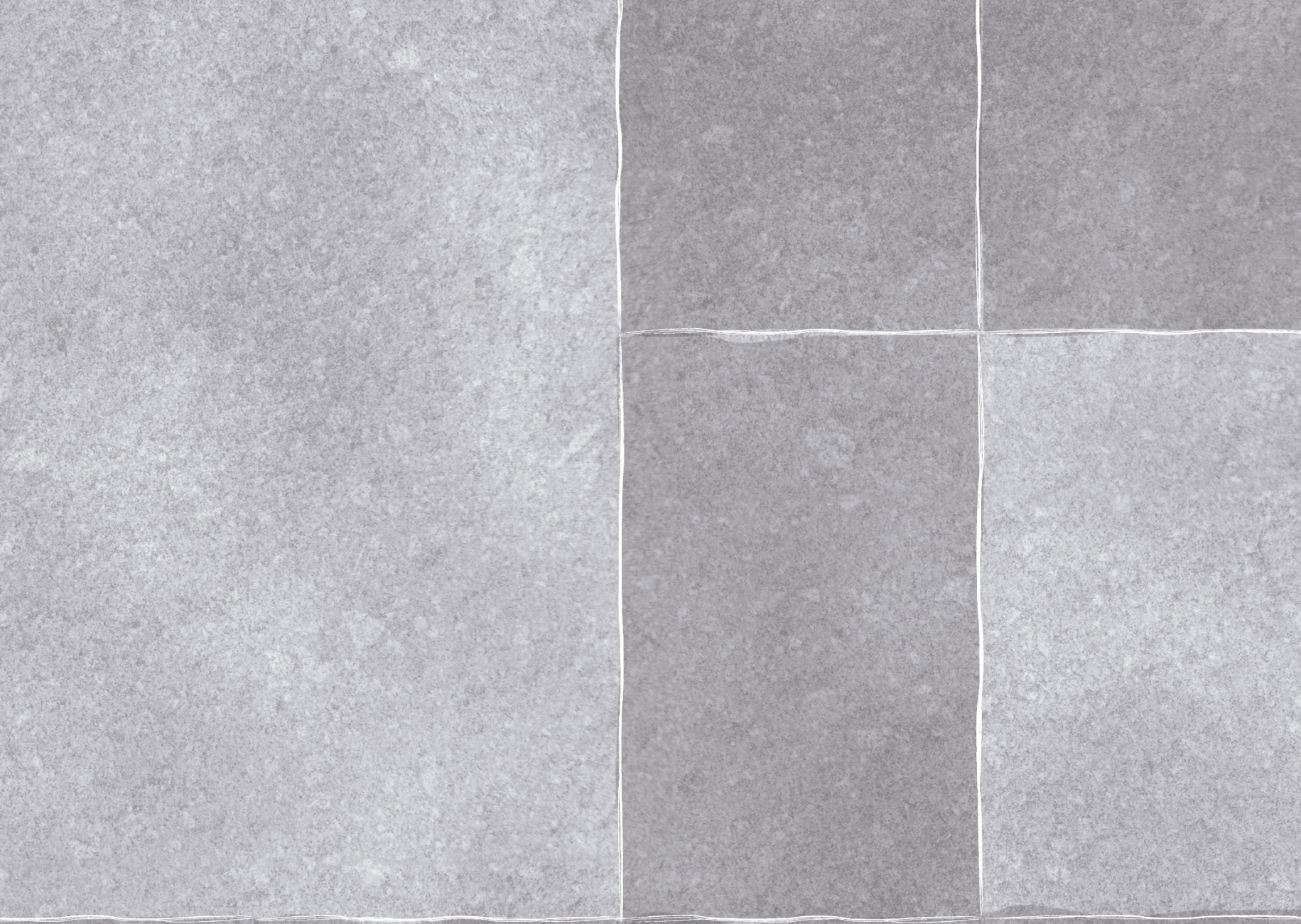




\section{Influência da Violência Dentro e Fora da Escola na Proficiência Escolar dos Alunos da Cidade do Recife}

\section{Joebson Maurilio Alves dos Santos}

Doutorando em economia pela Universidade Federal de Pernambuco (UFPE). Mestre em economia pela UFPE. Economisto pelo UFPE.

\section{Rubens Lopes Pereira da Silva}

Mestre em Economia pela Universidade Federal de Pernambuco (UFPE). Membro do Núcleo de Estudo Regionais e Urbanos (NERU).

\section{Flávia Emília Cavalcante Valença Fernandes}

Doutora em Inovaçõo Teropêutica pela Universidade Federal de Pernambuco (UFPE). Mestre em Gestõo e Economio da Saúde pelo UFPE. Professora Adjunto do Colegiado de Enfermagem da Universidade de Pernambuco (UPE) Compus Petrolino.

\section{Tatiane Almeida de Menezes}

Doutorado em Economio - USP. Pós-Doutorados: Yale University (2004) e London School of Economics (2016). Atualmente é Professora Associada do Departamento de Economia da UFPE e pesquisadora CNPq. Atua na graduação e na pós-graduação, na área de Economio Regional e Urbano.

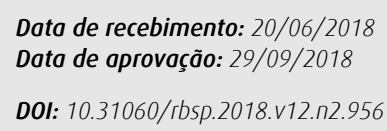

Resumo

o impacto do violêncio sobre o desempenho escolar dos alunos pode acarretar uma geração de trabalhadores com baixo produtividade e com esperança de salórios menores no futuro. Este trabalho procurou identificar como a violência afeto o proficiência dos alunos das escolas municipais da cidade do Recife. Desse modo, usando técnicas de georreferenciamento de dados e modelos hierárquicos, o trabalho mensurou a influência da violêncio dentro e fora da escola sobre o rendimento dos alunos, além de copturar o efeito do ambiente fomiliar e escolar. Tol análise foi possível, uma vez que os modelos hierárquicos permitem decompor a variôncio da proficiêncio escolar entre características inerentes oo aluno e ò escola, encontrando, assim, o "efeito-escola". Os resultados mostraram que a violência ocorrida fora das escolas, caracterizado pelos homicídios ocorridos no entorno, têm impacto negativo sobre o desempenho escolar e que oproximadamente 6,5\% do desempenho do estudante, medidos pelo coeficiente de correlação introescolar, deve-se à diferença entre escolas.

Palavras -Chave

Recife; Violêncio; Proficiêncio escolar; Modelos hierórquicos. 


\section{Abstract \\ Influence of violence in and out of school in the school proficiency of students in the city of Recife}

The impact of violence on students' school performance may lead to a generation of workers with low productivity and hoping for lower wages in the future. This work aimed to identify how violence affects the proficiency of students in the municipal schools of the city of Recife. Thus, using data georeferencing techniques and hierarchical models, the work measured the influence of violence inside and outside the school on the students' income, in addition to capturing the effect of the family and school environment. Such analysis was possible, since the hierarchical models allow decomposing the variance of the school proficiency between characteristics inherent to the student and to the school, thus finding the "school effect". The results showed that violence occurring outside schools, characterized by homicides occurring in the surroundings, have a negative impact on school performance, and that approximately $6.5 \%$ of the student's performance, meosured by the in-school correlation coefficient, is due to the difference between schools.

\section{Keywords}

Recife; Violence; School proficiency; Hierarchical models. 


\section{INTRODUÇÃO}

A educação sempre se mostrou como elemento chave na promoçáo do desenvolvimento dos agentes econômicos, pois está associada a uma maior produtividade e a uma esperança de maiores remuneraçóes no futuro. Nesse sentido, Romer (2006) argumenta que o crescimento econômico, no longo prazo, tem no capital humano um importante fator.

Para que o investimento em educação alcance seus objetivos (de desenvolvimento pessoal e de diminuição da violência), precisa-se saber quais fatores podem influenciar o desempenho escolar. Para Ferrão e Fernandes (2000), o desempenho escolar pode ser afetado por diversos fatores associados à estrutura social em que os alunos vivem, além das características individuais dos próprios alunos. Seguindo esse raciocínio, Gama e Scorzafave (2013) mostraram que a proficiência escolar pode ser afetada pela violência urbana que promove danos físicos e psicológicos aos alunos que sofrem demasiada exposição a ela.

Becker (1968) e Brueckner (2011) argumentam que quanto menor os ganhos com a atividade lícita, em comparação com os ganhos das atividades ilícitas, maior a probabilidade de os indivíduos cometerem crimes. Desta forma, o investimento em capital humano, pela via da educação, pode ser um fator relevante para a redução da violência. Em resumo, um ambiente cercado de criminalidade prejudica o aprendizado que, por sua vez, reduz a expectativa de ganhos com o trabalho lícito elevando a probabilidade da criança ser levada à criminalidade.

Neste contexto, o artigo se propóe a mensurar de que forma o número de assassinatos no entorno da escola pode influenciar o desempenho escolar do aluno, controlando os efeitos do background familiar e da estrutura escolar, além da violência ocorrida dentro da escola. Para tanto, aplicou-se um modelo hierárquico linear a um banco de dados único coletado pela Fundação Joaquim Nabuco (FUNDAJ), no qual está disponível a nota das provas de matemática com alunos do $6^{\circ}$ ano de uma amostra representativa das escolas de Recife, para o ano de 2013. Juntou-se a este banco, a base fornecida pela Secretaria de Defesa Social de Pernambuco (SDS/PE). Esta contém o número de crimes violentos letais intencionais (CVLI) georreferenciados. As informaçóes georreferenciadas permitem que se conheça a quantidade de homicídios que ocorreu no entorno de cada escola para, a partir disso, identificar 
o tipo de associação destes com o desempenho escolar.

O estudo está organizado em mais quatro seçôes, além desta introdução. $\mathrm{Na}$ seção 2, tem-se o referencial teórico, onde apresenta-se o arcabouço teórico que norteia a análise da violência no entorno de ambientes escolares. A seção 3 apresenta os dados utilizados neste trabalho à luz da literatura existente que motivou o a escolha dos mesmos. Na seçáo 4, tem-se a metodologia onde se fará a introdução aos métodos que avaliam diferentes efeitos no desempenho escolar a partir da estrutura hierárquica em que esses dados se apresentam. Na seção 5, apresentam-se os resultados e as discussóes acerca do problema levantado. Por fim, na seção 6 , são apresentadas algumas consideraçóes finais sobre os dados, o método utilizado e suas limitações, além dos resultados obtidos.

\section{Referencial Teórico}

A preocupação com os diversos fatores que podem afetar o desempenho escolar motivou a realizaçáo de diversos trabalhos que buscaram identificar tais fatores e apontar qual desses tem efeito negativo sobre a proficiência dos alunos para que, a partir disso, políticas eficazes de melhoria no sistema educacional fossem discutidas e implementadas. Com base nisso, Monteiro (2013), verificou, utilizando as notas da prova de matemática do Programme for International Student Assessment (PISA), dos alunos das escolas portuguesas, se havia um efeito significativo da escola a qual o aluno pertencia em seu desempenho escolar. Assim, fazendo uso de modelos hierárquicos, devido à natureza agrupada dos dados, a autora concluiu que não só as escolas como também o nível socioeconô- mico e cultural dos alunos são elementos importantes na determinação do desempenho escolar dos alunos portugueses.

Aplicando modelos de regressão multinível para os dados do PISA 2000, com alunos do Peru, Gutierrez (2005) realizou um estudo para verificar o efeito da escola no desempenho dos alunos, e concluiu que existe um efeito-escola significativo, mesmo quando o desempenho dos alunos é controlado pelo capital cultural e pelo capital econômico, ao nível do aluno, e controlando também pelo capital cultural médio, ao nível da escola. Evidências empíricas mostraram que a violência afeta negativamente a proficiência escolar. Macmillan e Hagan (2004) concluíram que alunos expostos à violência tiveram seus desempenhos escolares prejudicados, bem como houve diminuição na esperança de elevados rendimentos no futuro.

Bowen e Bowen (1999), utilizando outras formas de mensurar o efeito da violência, analisaram o impacto dos crimes dentro e fora do ambiente escolar e concluíram que a violência fora (no entorno) da escola tinha uma relaçáo negativa com o desempenho escolar e pode ser considerada mais nociva que a violência dentro da escola, confirmando, assim, as evidências da community violence nos resultados escolares.

No Brasil, diversos estudos procuraram identificar quais os determinantes da proficiência escolar. Ribeiro e Koslinski (2013) afirmaram que há uma nova geração de estudos que, baseados na sociologia urbana e da educação, tentam explicar como a organização social do território afeta as oportunidades educacionais. Des- 
se modo, esses autores mostraram que há efeitos do que eles chamam de modelo de segregação residencial (levando em consideração a grande presença de favelas em bairros abastados do Rio de janeiro) sobre o desempenho escolar.

Ainda na seara das possíveis causas do baixo desempenho escolar associados a fatores externos à escola (vizinhança), Gama e Scorzafave (2013) analisaram como a violência, no entorno das escolas, afeta o desempenho escolar na cidade de Sáo Paulo. Para isso, os autores verificaram os efeitos da violência de modo geral, que é conhecido na literatura internacional como community violence. Segundo esses autores, se trata de uma violência continuada a qual as pessoas estejam frequentemente expostas. Essa exposição pode ser não só como vítima, mas também como testemunha ou até mesmo por ter contato com pessoas vítimas de violência. A violência pode afetar os agentes por diversos canais distintos que, ainda de acordo com Gama e Scorzafave (2013), pode ser:

1. pela via física e psicológica, que traz sérias consequências para o desenvolvimento tanto emocional quanto comportamental das pessoas, principalmente crianças e adolescentes;

2. pela via social, que argumenta no sentido de que a violência que pode estar afetando a proficiência escolar é oriunda das diferenças socioeconômicas entre grupos;

3. pela via econômica, que aponta os choques econômicos como causa de violência em massa como conflitos armados e guerras;

4. pela via da supressão das condiçóes de ensino na escola, que é quando as escolas são impedidas de funcionar por conta da violência.

Assim, utilizando dados da Prova Brasil para os alunos do $5^{\circ}$ e do $9^{\circ}$ ano, e os dados de crimes da Fundação Sistema Estadual de Análise de Dados (Seade), além dos dados do censo demográfico de 2000 e da renda média dos chefes de família, esses autores, através da estimação de regressôes quantílicas, concluíram que o efeito da community violence se mostrou de pequena magnitude para os alunos do $5^{\circ}$ ano e praticamente nulo para alunos do $9^{\circ}$ ano. Eles seguiram argumentando que o efeito nulo observado com os alunos do $9^{\circ}$ ano se deve ao fato de que a violência parece estimular a evasão dos alunos mais velhos e não a redução do desempenho escolar.

Sant'Anna e Salata (2009) estudando os impactos do efeito vizinhança sobre os resultados escolar lançaram a seguinte argumentação:

A relevância do estudo do efeito vizinhança deve-se à crescente concentração de pobreza em áreas urbanas nas últimas décadas. A investigação dos efeitos dessa pobreza, territorializada, sobre resultados escolares passa, assim, a ser tratada como importante tarefa para a compreensáo dos processos que reproduzem desigualdades sociais. (p.01).

Esses autores utilizaram como variáveis independentes de interesse aquelas que caracterizam os locais de moradia e o nível socioeconômico dos moradores dos bairros da cidade do Rio de Janeiro e chegaram à conclusão de que as variáveis indicadoras do local de moradia têm influência na variável dependente, que foi construída a partir de informaçóes sobre as condiçóes de estudo e empregabilidade 
dos jovens cariocas com idade entre 15 e 19 anos. Esses autores argumentaram que as condiçôes socioeconômicas dos locais de moradia influenciam a decisão dos jovens no tocante a trabalhar ou estudar (ou ambos) e também a proximidade que tais locais têm com o centro da cidade, onde estão maiores ofertas de emprego, tem papel relevante nessa decisão.

Ferrão e Fernandes (2000), utilizando dados do Sistema de Avaliação da Educação Básica, SAEB da disciplina de matemática para alunos do $9^{\circ}$ ano (antiga $8^{\circ}$ série), em uma amostra da região sudeste (estados de Minas Gerais, Espírito Santo, Rio de Janeiro e São Paulo), concluíram, após a aplicação de modelos multinível, que alunos de escolas municipais têm desempenho semelhante aos alunos de escolas estaduais, e que alunos das escolas particulares apresentam desempenho superior, porém jugaram que o poder do modelo era limitado devido aos valores elevados dos componentes de variância.

\section{Dados}

Os dados que mesuram a proficiência dos alunos das escolas municipais da cidade do Recife são as notas obtidas na avaliação de matemática, aplicada a alunos do $6^{\circ}$ ano (antiga $5^{\circ}$ série), promovida pela FUNDAJ no final do ano letivo de 2013 nas escolas da rede municipal de ensino na cidade do Recife. Para Gama e Scorzafave (2013), O fato de se trabalhar com alunos do $6^{0}$ ano minimiza o viés de simultaneidade entre desempenho escolar e crimes, uma vez que é pouco provável que pessoas táo jovens cometam crimes, principalmente os de natureza grave como homicídios.

Os dados utilizados como proxy para mensuração da violência foram os homicídios intencionais no ano de 2008-2010 na cidade do Recife, uma vez que esse é o tipo de crime que apresenta a menor taxa de sub-registros (SANTOS; KASSOUF, 2007). A defasagem dos homicídios em relação à nota constitui uma limitação da base de dados utilizada neste trabalho, porém seu uso se justifica, segundo Gama e Scorzafave (2013), porque essa defasagem minimiza problemas de endogeneidade entre a ocorrência dos homicídios e a proficiência escolar.

As demais variáveis utilizadas foram divididas em dois grupos: varáveis das características dos alunos e variáveis das características da escola. No primeiro grupo têm-se as variáveis que representam as características físicas dos alunos como sexo (Sex), idade (Age) e raça (Race) (ARAUJO; SIQUEIRA, 2010). Além disso, utilizou-se a nota do aluno obtida na prova de matemática aplicada pelos pesquisadores da FUNDAJ, no início do ano letivo (2013), como uma proxy da habilidade (Note1), pois alunos que já tinham um bom desempenho em matemática tendem a repetir esse desempenho nos anos subsequentes (ARRUDA, 2017).

Ainda no primeiro grupo, têm-se as variáveis do contexto familiar que, como destacam Ferrão (2003) e Sant'Anna e Salata (2009), podem ser importantes preditores do desempenho escolar do aluno. Assim, utilizou-se o sexo (Parsex), a idade (Parage) e o nível de escolaridade do responsável pelo aluno (Parschool) e as variáveis (Desktop) que informa se o aluno possui computador em casa, e (Bolfam) que informa se sua família é beneficiária do Programa Bolsa Família. 
Já para o segundo grupo (variáveis das características das escolas), utilizou-se variáveis representativas da estrutura física, da qualidade do corpo docente e da gestáo escolar e, também, da violência dentro e no entorno das escolas. As variáveis que caracterizam a estrutura física se mostram relevantes nos determinantes do desempenho escolar (ARRUDA, 2017; ARAUJO; SILVEIRA NETO, 2018). As variáveis foram: laboratório (Lab), auditório (Audit), quadra de esportes (Quadra), sala de música (Musroom) e acesso à internet (Net). Para o corpo docente, utilizou-se idade (Agep1), que informa se o professor tem até 29 anos de idade, sexo (Sexp), raça (Racep), tipo de instituição que o professor se formou (Inst_pub), que informa se foi numa instituiçáo pública ou privada, e se este passou por curso de capacitação (capac). Para a gestão, utilizou-se sexo (Sexd) e raça do diretor (Raced), se ele possui especialização em gestão escolar (Posgest), além da informaçáo de se a escola tem programas de reforço escolar (progrefor) e controle de reprovaçóes (contrepr).

A qualidade do corpo doente e da gestáo escolar tem sido bastante debatida e explorada nas pesquisas empíricas com vistas a identificar seus efeitos sobre o aprendizado e sobre as notas obtidas pelos estudantes, uma vez que tais fatores podem ser relevantes na determinação do sucesso escolar (HANUSHEK, 1970; ALVES; SOARES, 2008; ALMEIDA, 2014; ARAUJO; SILVEIRA NETO, 2018).

A convivência com a violência pode ser bastante nociva a pessoas mais jovens, o que pode se refletir no seu desempenho escolar (GAMA; SCORZAFAVE, 2013), e a violência no entorno das escolas po- dem ter um impacto de maior magnitude na proficiência do aluno (BOWEN E BOWEN, 1999). As variáveis escolhidas para representar a violência dentro da escola foram: se escola sofreu depredaçáo (Depred) e se houve consumo de drogas nas dependências das escolas nos dois últimos anos (Drog), enquanto para a violência do entorno escolar foi utilizado o número de homicídios ocorridos num raio de $750 \mathrm{~m}$, $1000 \mathrm{~m}$ e $1250 \mathrm{~m}$ das escolas.

Em grandes cidades como Recife, os alunos da rede pública de ensino são matriculados, geralmente, nas escolas próximas as suas residências, pois isso evita, entre outras coisas, gastos com transporte para escolas mais distantes. Araújo e Silveira Neto (2018) estimou que a distância entre a moradia dos alunos da rede municipal e escolas em que estudam é, em média, de $850 \mathrm{~m}$ na cidade do Recife.

Uma forma de captar a influência dos homicídios no desempenho escolar dos alunos é considerar os crimes num raio de $750 \mathrm{~m}$ a $1250 \mathrm{~m}$ das escolas em que eles estudam. Isso foi conseguido a partir do endereço da ocorrência dos homicídios, onde foram extraídas, através do georreferenciamento dos dados, as coordenadas geográficas que mostram a localização exata desses homicídios para, a partir daí, saber a proximidade destes com as escolas como ilustra a Figura 1.

\section{Metodologia}

\section{Modelos Lineares Hierárquicos ou Mul- tinível}

Ferrão (2003) e Monteiro (2013), argumentam que a melhor forma de se mensurar os impactos dos possíveis fatores 
que podem afetar a proficiência dos alunos é a utilização de modelos lineares hierárquicos, pois estes levam em consideração a estrutura hierárquica com que os dados se apresentam. Portanto, considera-se os alunos como unidade micro que, por sua vez, estão agrupados em escolas, consideradas como unidade macro. $\mathrm{Na}$ unidade micro, serão consideradas as variáveis inerentes às características dos alunos e do background familiar e no nível macro serão consideradas as variáveis inerentes às características da escola como infraestrutura física, características dos docentes e o nível de violência dentro e no entorno de cada uma delas.

Figura 1 - Homicídios no entorno das escolas municipais de Recife-Pernambuco, 2008-2010

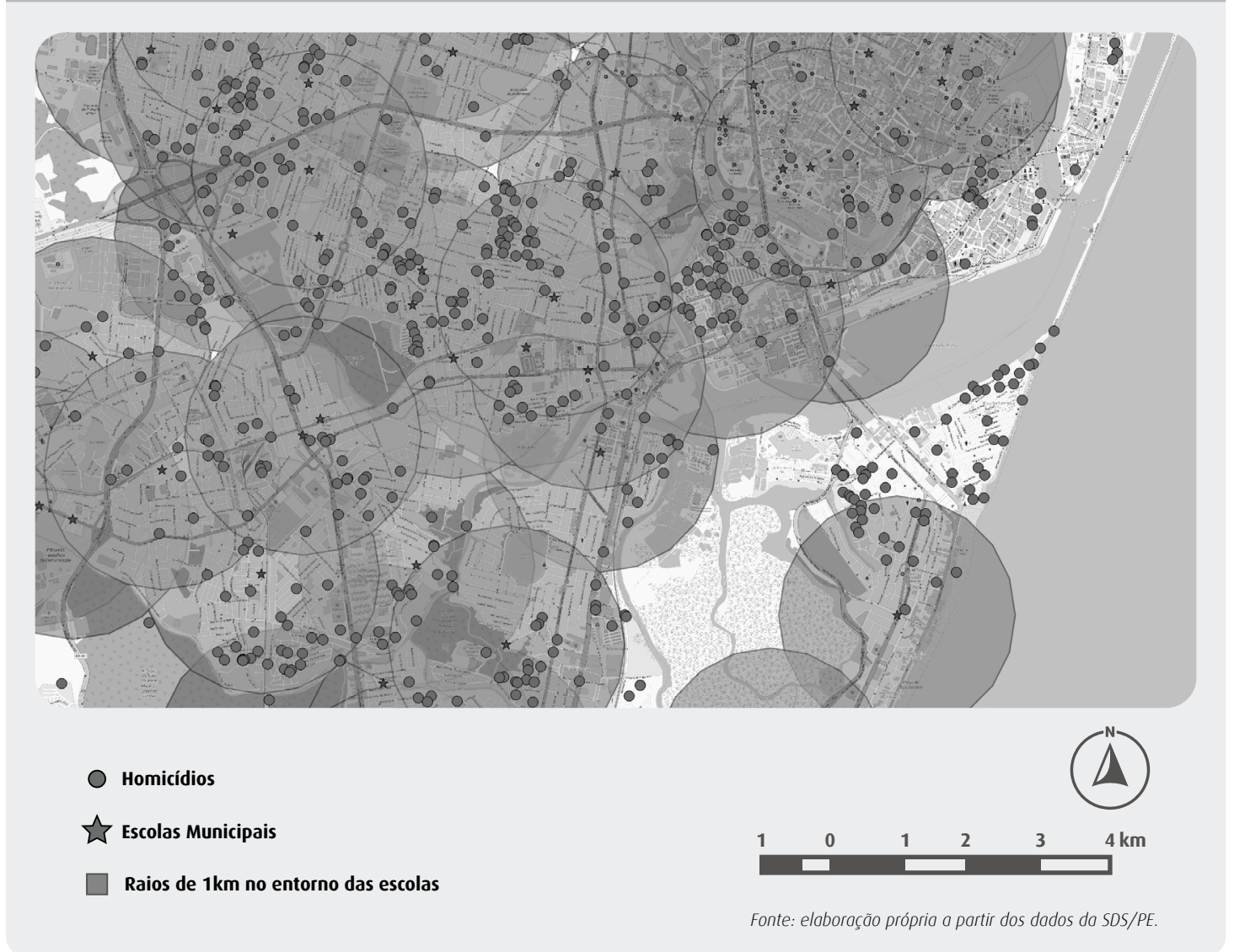

A utilização de modelos de regressão multinível com dois níveis permite considerar a escola como um fator que pode afetar o desempenho dos alunos. Raudenbush and Bryk (2002) elencam algumas etapas para a análise multinível. Tal análise é feita a partir de um modelo chamado Modelo de Componentes de Variância que, por sua vez, se divide em modelo nulo e modelos de efeitos fixos.
Denomina-se o primeiro como modelo nulo porque este não envolve nenhuma variável explicativa em nenhum dos níveis da análise, ou seja, o preditor linear é apenas o intercepto. Cruz (2010) afirma a importância desse modelo, pois ele permite o estudo da distribuiçáo da variância total da variável dependente pelos diversos níveis de agrupamento. 
Modelo nulo

$$
\begin{gathered}
\text { Proficiência } i j=\beta_{0 j}+\epsilon_{i j} . \\
\beta_{0 j}=\gamma_{00}+u_{0 j},
\end{gathered}
$$

onde

Proficiência $_{i j}$ representa a variável resposta do aluno i na escola $\mathrm{j}$;

$\beta_{0 \mathrm{j}}$ representa a média da variável resposta na j-ésima escola;

$\gamma_{00}$ representa a média global da variável resposta;

$\epsilon_{\mathrm{ij}}$ é o erro aleatório associado ao i-ésimo aluno da escola j e $\epsilon_{\mathrm{ij}} \sim \mathrm{N}\left(0 ; \sigma_{\epsilon}^{2}\right)$ e são independentes;

$u_{0 \mathrm{j}}$ é o erro aleatório associado à escola $\mathrm{j}$ e $u_{0 \mathrm{j}} \sim \mathrm{N}\left(0 ; \sigma_{\epsilon 0}^{2}\right)$ e são independentes.

A variância da proficiência decompóe-na em dois termos independentes,

$\operatorname{Var}($ Proficiência $)=\operatorname{var}\left(u_{0 j}+\epsilon_{i j}\right)=\sigma_{u 0}^{2}+\sigma_{\epsilon}^{2}$,

onde $\sigma_{u 0}^{2}$ mede a variância entre escolas e $\sigma_{\epsilon}^{2}$ mede a variância intraescola. Se $\sigma_{u 0}^{2}$ for estatisticamente igual a zero, toda a variabilidade do desempenho escolar será atribuída a diferença entre alunos, ou seja, não haverá o efeito-escola. Este modelo ainda permite definir o coeficiente de correlação intraescolar que indica a percentagem da variância total que é explicada pelo fator escola.

\section{O coeficiente de correlação intraescolar}

Essa estatística mede a proporção da variância entre escolas em relação à variância total da proficiência.

$$
\rho=\frac{\sigma_{u 0}^{2}}{\sigma_{u 0}^{2}+\sigma_{\epsilon}^{2}} .
$$

Quando o valor desse coeficiente é nulo, significa que a proficiência escolar se deve a características dos alunos, pois as escolas são homogêneas entre si. Quando é igual a um, toda a variabilidade do desempenho escolar se deve as diferenças entre as escolas, ou seja, as características dos alunos não exercem influência em seus desempenhos. Este coeficiente é usado como estimador do efeito-escola. Uma vez confirmada a existência do efeito-escola, deve-se estimar esse efeito ante a presença de variáveis que caracterizam os alunos, pois ter-se-á uma estimativa mais confiável do efeito-escola. Para esse fim, usa-se um modelo que leva em consideração as variáveis com as características dos alunos e, na sequência, da escola.

\section{Modelos de efeitos fixos}

\section{Modelo de efeito fixo Individual}

Este modelo tem $\mathrm{k}$ variáveis introduzidas ao nível 1 , ou seja, ao nível do aluno.

$$
\begin{gathered}
\text { Proficiência }_{i j}=\beta_{0 j}+\beta_{1} X_{1 i j}+\beta_{2} X_{2 i j}+\cdots+\beta_{k} X_{k i j}+\epsilon_{i j} . \\
\beta_{0 j}=\gamma_{00}+u_{0 j} .
\end{gathered}
$$

$\sum \beta_{\mathrm{j}} X_{\mathrm{ij}}$ representa características dos alunos incorporadas ao modelo.

Ele permite observar como se altera o efeito-escola à medida em que são incluídas variáveis que representam as características individuais dos alunos.

Pode-se expandir o modelo de efeitos fixos para que este englobe variáveis que expressem o contexto escolar. 
Modelo de efeito fixo Contextual

Este modelo tem $\mathrm{k}$ variáveis introduzidas ao nível do aluno e ao nível da escola.

$$
\begin{gathered}
\text { Proficiência }_{i j}=\beta_{0 j}+\beta_{1} X_{1 i j}+\beta_{2} X_{2 i j}+\cdots+\beta_{k} X_{k i j}+\epsilon_{i j} . \\
\beta_{0 j}=\gamma_{00}+\gamma_{01} E_{1}+\cdots+\gamma_{0 k} E_{k}+u_{0 j} .
\end{gathered}
$$

$\sum \beta_{\mathrm{j}} X_{\mathrm{ij}}$ representa características dos alunos incorporadas ao modelo e $\sum \gamma_{0 \mathrm{j}} E_{\mathrm{ij}}$ representam características das escolas incorporadas ao modelo.

Ele é usado para mensurar o efeito que a escola exerce sobre o comportamento individual do aluno. Será nesse nível (da escola) que as variáveis referentes à violência associada ao entorno e ao ambiente escolar, além de outras que definem as características das escolas, serão incorporadas ao modelo.

Para Fávero et al. (2014), devido à natureza náo balanceada na maioria dos dados agrupados em níveis de hierarquia, a estimaçáo dos componentes de variância pelos métodos tradicionais falha e, por isso, tem-se de fazer uso da estimaçáo de máxima verossimilhança.

\section{Coeficiente de Determinação}

Uma medida do ajustamento do modelo, ao se adicionar regressores ao nível do aluno e da escola, é o $\mathrm{R}^{2}{ }_{1}$ e o $\mathrm{R}^{2}{ }_{2}$ que são especificados como segue:

$$
R_{1}^{2}=\frac{\sigma_{\epsilon}^{2}(0)-\sigma_{\epsilon}^{2}(1)}{\sigma_{\epsilon}^{2}(0)}
$$

onde $\sigma_{\epsilon}^{2}(0)$ é a variância intraescola do modelo nulo e $\sigma_{\epsilon}^{2}$ (1) é a variância intraescola do modelo de comparaçáo. Explica a melhoria percentual da variabilidade da variável resposta explicada pela inclusão das variáveis ao nível do aluno face ao modelo nulo.

$$
R_{2}^{2}=\frac{\sigma_{u o}^{2}(0)-\sigma_{u 0}^{2}(1)}{\sigma_{u 0}^{2}(0)},
$$

onde $\sigma_{u 0}^{2}(0)$ é a variância entre escolas do modelo nulo e $\sigma_{u 0}^{2}$ (1) é a variância entre escolas do modelo de comparação. Explica a melhoria percentual da variabilidade da variável resposta explicada pela inclusáo das variáveis ao nível da escola face ao modelo nulo.

\section{Resultados e Discussão}

\section{Análise Descritiva}

$\mathrm{Na}$ Tabela 1 , tem-se as estatísticas descritivas variáveis das características dos alunos e do seu background familiar com seus valores médios e o desvio padrão correspondente. Já na Tabela 2, tem-se as estatísticas descritivas das características físicas, dos docentes e do gestor da escola e também das variáveis representativas da violência dentro e no entorno dela. Mais uma vez, a tabela traz a média e o desvio padrão das variáveis citadas.

\section{Estimação do Modelo Hierárquico}

Os resultados no modelo nulo mostram que a estimativa da média global da proficiência, que é o intercepto vertical, $\gamma_{00}$, é de 39,82 pontos e a estimativa da variância entre escolas, $\sigma_{u 0}^{2}$, é de 41,37 , enquanto a estimativa da variância intraescola, $\sigma_{\epsilon}^{2}$, ou seja, aquela que é devido à diferença entre alunos da mesma escola é de 201,35. Essa decomposição da variância nos permite calcular o coeficiente de correlaçáo intraescolar, $\rho$, que no modelo estimado é de 0,170. Esse resultado sugere que $17,0 \%$ da variabilidade da nota dos 
alunos se deve a diferença entre escolas, porém o resultado dessa estatística é pre- maturo e exige que variáveis de controle sejam adicionadas ao modelo.

Tabela 1 - Estatística descritiva das variáveis das características e do background familiar dos alunos das escolas municipais da cidade do Recife no ano de 2013.

\begin{tabular}{l|l|c|c}
\multicolumn{1}{c|}{ Nível Aluno } & \multicolumn{1}{c|}{ Descrição } & Média & Desvio Padrão \\
\hline Variáveis & & 0.490 & 0.499 \\
\hline Sex & Dummy=1 se sexo do aluno é masculino & 11.31 & 1.016 \\
\hline Age & Idade do aluno & 0.187 & 0.390 \\
\hline Race & Dummy=1 se aluno é branco & 41.19 & 16.05 \\
\hline Note1 & Nota do aluno na prova de matemática obtida no ano anterior à pesquisa & 40.15 & 15.73 \\
\hline Note2 & Nota do aluno na prova de matemática no ano da pesquisa. & 0.137 & 0.344 \\
\hline Parsex & Dummy=1 se sexo do responsável pelo aluno é masculino & 38.72 & 8.42 \\
\hline Parage & Idade do responsável pelo aluno & 8.58 & 3.66 \\
\hline Parschool & Anos de estudo concluído do responsável pelo aluno & 0.616 & 0.486 \\
\hline Desktop & Dummy=1 se aluno tem computador em casa & 0.565 & 0.495
\end{tabular}

Tabela 2 - Estatística descritiva das variáveis que caracterizam a estrutura física, a gestão escolar e a violência dentro e fora das escolas municipais da cidade do Recife no ano 2013.

\begin{tabular}{|c|c|c|c|}
\hline \multicolumn{4}{|c|}{ Nível Escola } \\
\hline Variáveis & Descrição & Média & Desvio Padrão \\
\hline Agep1 & Dummy=1 se a idade do professor é de até 29 anos & 0.181 & 0.385 \\
\hline Sexp & Dummy=1 se sexo do professor é masculino & 0.326 & 0.468 \\
\hline Racep & Dummy=1 se professor é branco & 0.187 & 0.390 \\
\hline Capac & Dummy=1 se professor fez curso de capacitação & 0.887 & 0.316 \\
\hline Isnt_pub & Dummy=1 se professor se formou em instituição pública de ensino & 0.187 & 0.390 \\
\hline Sexd & Dummy=1 se sexo do diretor é masculino & 0.346 & 0.475 \\
\hline Raced & Dummy=1 se diretor é branco & 0.332 & 0.471 \\
\hline Posgest & Dummy=1 se a pós-graduação do diretor é em gestão escolar & 0.356 & 0.479 \\
\hline Progrefor & Dummy=1 se escola tem programa de reforço escolar & 0.925 & 0.262 \\
\hline Contrepr & Dummy=1 se escola tem controle de reprovação & 0.904 & 0.293 \\
\hline Lab & Dummy=1 se existe laboratório na escola & 0.687 & 0.463 \\
\hline Audit & Dummy=1 se existe auditório na escola & 0.745 & 0.435 \\
\hline Quadra & Dummy $=1$ se se existe quadra de esportes na escola & 0.677 & 0.467 \\
\hline Musroom & Dummy=1 se existe sala de estudo de música na escola & 0.723 & 0.447 \\
\hline
\end{tabular}




\begin{tabular}{|c|c|c|c|}
\hline Net & Dummy=1 se se há acesso à internet para os alunos & 0.486 & 0.499 \\
\hline Depred & Dummy=1 se escola sofreu depredação nos dois últimos anos & 0.696 & 0.459 \\
\hline Drog & Dummy $=1$ se constatou consumo de drogas na escola nos dois ultimos anos & 0.580 & 0.493 \\
\hline Crime750 & Homicídios em um raio de $750 \mathrm{~m}$ das escolas & 20.43 & 12.20 \\
\hline Crime 1000 & Homicídios em um raio de $1000 \mathrm{~m}$ das escolas & 36.90 & 18.78 \\
\hline Crime1250 & Homicídios em um raio de $1250 \mathrm{~m}$ das escolas & 54.90 & 24.76 \\
\hline
\end{tabular}

Fonte: elaboraçõo própria o partir dos dados do FUNDAJ e SDS/PE.

$\mathrm{Na}$ sequência, estimou-se o modelo com variáveis que carregam características dos alunos, o modelo aluno na coluna 2 da Tabela 3. Nesse modelo, a média global da proficiência passa a ser de 41,04. A variável computador no domicílio do aluno, representada por desktop, tem correlaçáo positiva com o desempenho escolar, assim como o nível de escolaridade do responsável pelo aluno, representada pela variável parschool e a proxy para habilidade inata representada pela variável note1. Esses resultados mostram que ter ferramentas que facilitam o aprendizado, como um computador e ter pais com maiores níveis educacionais influenciam positivamente $o$ desempenho escolar dos alunos.

O uso da proxy note1 teve como objetivo capturar um efeito náo observado pelo pesquisador que é a habilidade inata do aluno. $\mathrm{O}$ resultado mostra que alunos que tiveram um bom desempenho em matemática tende a mantê-lo nos períodos subsequentes. Essas variáveis apesar de serem fortemente correlacionadas não apresentam viés de simultaneidade, pois nota passada pode causar nota futura, mas não o contrário.

Já a idade do aluno tem uma correlaçáo negativa com sua proficiência e isso pode caracterizar uma distorção idade-sé- rie. Isso ocorre quando os alunos estão fora da idade adequada para determinada série, quer seja porque repetiram de ano ou porque começaram a estudar tarde. Resultado similar é encontrado em Ferrão e Beltrão (2001) que também verificaram uma relação negativa entre a idade do aluno e seu desempenho escolar e Ferrão (2003) faz uma discussão mais detalhada a distorção idade-série. Diante do acréscimo das variáveis do background familiar do aluno ao modelo, o coeficiente de correlaçáo intraescolar diminui para 0,078. Isso mostra que $7,8 \%$ da variância das notas é devido à diferença entre escolas.

Acrescentando as variáveis que caracterizam o ambiente escolar e os homicídios no entorno das escolas, no modelo crime $750 \mathrm{~m}$, verificou-se que as variáveis com características dos docentes e do gestor da escola não tiveram significância estatística e para as variáveis da infraestrutura escolar, as variáveis Musroom e Net tiveram significância ao nível de 5\%. Logo, acesso à internet e sala de estudos de música nas escolas tem influência positiva na nota dos alunos.

Uma limitaçáo desta pesquisa se deve ao fato de as escolas da amostra aqui utilizada serem todas da rede municipal de ensino, isso implica em certa homogenei- 
dade em termos de estrutura, docência, gestão. Logo, esses fatores podem não explicar a variabilidade das notas dos alunos dado que eles estáo expostos a estruturas físicas e de gestáo parecidas.

Mesmo com a limitação citada, os resultados estão em consonância com outros achados na literatura. Por exemplo, nesta pesquisa controlou-se o efeito da existência de programa de reforço escolar sobre a nota obtida pelos alunos e seu resultado não foi estatisticamente significante. Almeida (2014), utilizando microdados da Prova Brasil 2011, para escolas públicas da rede federal, estadual e municipal e controlando o efeito de diversas variáveis do background familiar, do corpo docente e da escola, encontra que ter programas de reforço na escola não é fator determinante sobre os resultados escolares. Além disso, as características dos alunos e o contexto socioeconômico das famílias têm maiores contribuiçóes para o desempenho escolar.

A pequena magnitude do efeito-escola sobre o desempenho escolar também pode ser vista em Alves e Soares (2008) que encontraram que o nível socioeconômico dos alunos tem um efeito positivo e forte sobre suas proficiências e que as escolas não conseguem mitigar essas diferenças dentro delas. Assim, esses autores sugerem a adoção de políticas públicas para que as escolas consigam ter um papel mais efetivo sobre o desempenho escolar para que se diminua o efeito da origem social nos resultados escolares, que é uma das principais fontes da desigualdade da trajetória escolar. Esse resultado é semelhante aos encontrados por Daly (1991) que encontrou efeito-escola de $7 \%$ a $11 \%$ para escolas secundárias na Irlanda do Norte.
Os homicídios no raio de 750m também não apresentaram significância estatística ao nível usual de 5\%. Essa primeira medida parece não captar todos os crimes que podem estar afetando o desempenho dos alunos, sendo, assim, subestimada, o que justifica sua não significância. $\mathrm{O}$ coeficiente de correlação intraescolar, após a inclusão das variáveis no nível 2 , mostra que $6,4 \%$ da variância da proficiência se deve à diferença entre escolas.

Nos modelos subsequentes, apenas variam o raio dos homicídios considerados. Quando são considerados os homicídios ocorridos em raio de $1000 \mathrm{~m}$, estes passam a apresentar significância estatística ao nível de 5\%, enquanto os homicídios ocorridos em um raio de $1250 \mathrm{~m}$ não são, pois passa-se a considerar crimes ocorridos muito distantes das escolas e que não têm influência na proficiência escolar. $\mathrm{O}$ coeficiente de correlação intraescolar pouco muda, mantendo-se em $6,4 \%$ no modelo final.

Dentre as variáveis utilizadas no nível da escola, apenas o acesso à internet, a presença de salas destinas a ensino de música e a violência do entorno foram significativas. Esse resultado pode ser devido às características mais ou menos homogêneas das escolas, uma vez que elas são todas pertencentes ao sistema municipal de ensino. A correlação negativa entre a violência do entorno e as notas dos alunos era esperada e também é verificada em Arruda (2017), Gama e Scorzafave (2013), Teixeira e Kassouf (2007) e Bowen e Bowen (1999).

O fato de se trabalhar com dados de homicídios georreferanciados constituiu um importante avanço na mensuraçáo da 
associação entre a violência e proficiência escolar, pois isto permitiu trabalhar com dados menos agregados do que os normalmente utilizados que são em nível de bairro. Dessa forma, alunos que estudam perto da fronteira entre bairros tinham apenas os crimes ocorridos no bairro onde estudam como uma das possíveis causas do seu insucesso escolar. Com o georreferenciamento, foi possível traçar raios no entorno das escolas, o que independe das fronteiras entre bairros, e contabilizar todos os crimes dentro desse raio para verificar a relação existente entre eles e as notas dos alunos.
Um problema que pode existir sobre a contabilização de crimes a partir de raios em torno de determinado ponto é que, em muitos casos, não é possível criar medidas padronizadas como, por exemplo, taxas, pois seriam necessários dados de toda a população georreferenciados, o que possibilitaria contar a quantidade de pessoas dentro de cada raio. Mesmo com tal limitação, esta técnica é largamente usada nos trabalhos aplicados como em Seabra, Silveira Neto e Menezes (2016), Arruda (2017), Araújo e Silveira Neto (2018) porque permite criar medidas de comparação entre diferentes níveis de agregaçáo de dados como forma de testar a robustez dos resultados encontrados.

Tabela 3 - Análise hierárquica da influência das características e background familiar dos alunos, qualidade escolar e da
violência dentro e fora da escola na proficiência dos alunos da rede municipal na cidade de Recife no ano de 2013.

\begin{tabular}{|c|c|c|c|c|c|}
\hline & $\begin{array}{l}(1) \\
\text { Nulo }\end{array}$ & $\begin{array}{c}\text { (2) } \\
\text { Aluno }\end{array}$ & $\begin{array}{c}\text { (3) } \\
\text { crime } 750 \mathrm{~m}\end{array}$ & $\begin{array}{c}(4) \\
\text { crime } 1000 \mathrm{~m}\end{array}$ & $\begin{array}{c}(5) \\
\text { crime } 1250 \mathrm{~m}\end{array}$ \\
\hline Sex & & $\begin{array}{l}0.198 \\
(0.42)\end{array}$ & $\begin{array}{l}0.189 \\
(0.40)\end{array}$ & $\begin{array}{r}0.185 \\
(0.40)\end{array}$ & $\begin{array}{l}0.190 \\
(0.41)\end{array}$ \\
\hline Age & & $\begin{array}{r}-1.823 \\
(-7.49)\end{array}$ & $\begin{array}{r}-1.819^{*} \\
(-7.48)\end{array}$ & $\begin{array}{r}-1.821 \\
(-7.49)\end{array}$ & $\begin{array}{r}-1.826^{\text {*m: }} \\
(-7.51)\end{array}$ \\
\hline Race & & $\begin{array}{l}-0.395 \\
(-0.67)\end{array}$ & $\begin{array}{l}-0.403 \\
(-0.68)\end{array}$ & $\begin{array}{l}-0.404 \\
(-0.69)\end{array}$ & $\begin{array}{l}-0.407 \\
(-0.69)\end{array}$ \\
\hline Note1 & & $\begin{array}{r}0.408^{\prime} \\
(25.71)\end{array}$ & $\begin{array}{r}0.405^{\prime *} \\
(25.45)\end{array}$ & $\begin{array}{r}0.405 \\
(25.43)\end{array}$ & $\begin{array}{r}0.405^{\prime} \\
(25.44)\end{array}$ \\
\hline Parsex & & $\begin{array}{l}0.429 \\
(0.62)\end{array}$ & $\begin{array}{l}0.389 \\
(0.56)\end{array}$ & $\begin{array}{l}0.390 \\
(0.56)\end{array}$ & $\begin{array}{l}0.391 \\
(0.56)\end{array}$ \\
\hline Parage & & $\begin{array}{r}0.00547 \\
(0.19)\end{array}$ & $\begin{array}{r}0.00690 \\
(0.24)\end{array}$ & $\begin{array}{r}0.00715 \\
(0.25)\end{array}$ & $\begin{array}{r}0.00671 \\
(0.23)\end{array}$ \\
\hline Parschool & & $\begin{array}{c}0.171^{*} \\
(2.53)\end{array}$ & $\begin{array}{c}0.170^{*} \\
(2.52)\end{array}$ & $\begin{array}{c}0.171^{*} \\
(2.52)\end{array}$ & $\begin{array}{l}0.170^{*} \\
(2.51)\end{array}$ \\
\hline Desktop & & $\begin{array}{r}2.395 \\
(4.88)\end{array}$ & $\begin{array}{r}2.412^{*} \\
(4.92)\end{array}$ & $\begin{array}{r}2.391^{*} \\
(4.87)\end{array}$ & $\begin{array}{r}2.398^{*} \\
(4.88)\end{array}$ \\
\hline Bolsafam & & $\begin{array}{l}-0.765 \\
(-1.54)\end{array}$ & $\begin{array}{l}-0.747 \\
(-1.50)\end{array}$ & $\begin{array}{l}-0.739 \\
(-1.49)\end{array}$ & $\begin{array}{l}-0.746 \\
(-1.50)\end{array}$ \\
\hline agep1 & & & $\begin{array}{l}-1.390 \\
(-1.20)\end{array}$ & $\begin{array}{r}-1.134 \\
(-0.99)\end{array}$ & $\begin{array}{l}-1.380 \\
(-1.19)\end{array}$ \\
\hline Sexp & & & $\begin{array}{l}0.763 \\
(0.77)\end{array}$ & $\begin{array}{l}0.793 \\
(0.81)\end{array}$ & $\begin{array}{l}0.673 \\
(0.68)\end{array}$ \\
\hline Racep & & & $\begin{array}{l}-0.786 \\
(-0.83)\end{array}$ & $\begin{array}{l}-0.731 \\
(-0.78)\end{array}$ & $\begin{array}{c}-0.834 \\
(-0.88)\end{array}$ \\
\hline Сарас & & & $\begin{array}{c}-0.373 \\
(-0.26)\end{array}$ & $\begin{array}{l}-0.509 \\
(-0.36)\end{array}$ & $\begin{array}{l}-0.425 \\
(-0.30)\end{array}$ \\
\hline
\end{tabular}




\begin{tabular}{|c|c|c|c|c|c|}
\hline Instit_pub & & & $\begin{array}{r}0.219 \\
(0.25)\end{array}$ & $\begin{array}{l}0.226 \\
(0.26)\end{array}$ & $\begin{array}{r}0.146 \\
(0.17)\end{array}$ \\
\hline Sexd & & & $\begin{array}{l}-0.364 \\
(-0.43)\end{array}$ & $\begin{array}{l}-0.374 \\
(-0.45)\end{array}$ & $\begin{array}{l}-0.393 \\
(-0.46)\end{array}$ \\
\hline Raced & & & $\begin{array}{r}0.851 \\
(0.95)\end{array}$ & $\begin{array}{r}0.797 \\
(0.91)\end{array}$ & $\begin{array}{c}0.863 \\
(0.97)\end{array}$ \\
\hline Posgest & & & $\begin{array}{r}-0.729 \\
(-0.83)\end{array}$ & $\begin{array}{l}-0.886 \\
(-1.02)\end{array}$ & $\begin{array}{l}-0.797 \\
(-0.90)\end{array}$ \\
\hline Progref & & & $\begin{array}{c}-0.256 \\
(-0.16)\end{array}$ & $\begin{array}{l}-0.333 \\
(-0.21)\end{array}$ & $\begin{array}{l}-0.108 \\
(-0.07)\end{array}$ \\
\hline Contrepr & & & $\begin{array}{r}0.247 \\
(0.16)\end{array}$ & $\begin{array}{l}0.337 \\
(0.22)\end{array}$ & $\begin{array}{r}0.0806 \\
(0.05)\end{array}$ \\
\hline Lab & & & $\begin{array}{l}-0.616 \\
(-0.68)\end{array}$ & $\begin{array}{l}-0.790 \\
(-0.88)\end{array}$ & $\begin{array}{l}-0.752 \\
(-0.83)\end{array}$ \\
\hline Audit & & & $\begin{array}{r}-1.136 \\
(-0.86)\end{array}$ & $\begin{array}{r}-1.166 \\
(-0.90)\end{array}$ & $\begin{array}{r}-1.032 \\
(-0.79)\end{array}$ \\
\hline Quadra & & & $\begin{array}{r}-0.0707 \\
(-0.07)\end{array}$ & $\begin{array}{r}0.0747 \\
(0.08)\end{array}$ & $\begin{array}{r}0.0883 \\
(0.09)\end{array}$ \\
\hline Musroom & & & $\begin{array}{r}2.511^{*} \\
(2.03)\end{array}$ & $\begin{array}{c}2.410^{*} \\
(1.97)\end{array}$ & $\begin{array}{c}2.477^{*} \\
(2.00)\end{array}$ \\
\hline Net & & & $\begin{array}{c}1.816 \\
(2.13)\end{array}$ & $\begin{array}{l}1.967^{*} \\
(2.32)\end{array}$ & $\begin{array}{l}1.883^{*} \\
(2.19)\end{array}$ \\
\hline Depred & & & $\begin{array}{l}-0.673 \\
(-0.71)\end{array}$ & $\begin{array}{l}-0.723 \\
(-0.77)\end{array}$ & $\begin{array}{l}-0.717 \\
(-0.75)\end{array}$ \\
\hline Drog & & & $\begin{array}{l}0.514 \\
(0.60)\end{array}$ & $\begin{array}{l}0.537 \\
(0.64)\end{array}$ & $\begin{array}{r}0.540 \\
(0.64)\end{array}$ \\
\hline crime $750 m$ & & & $\begin{array}{r}-0.0398 \\
(-1.17)\end{array}$ & & \\
\hline crime $1000 \mathrm{~m}$ & & & & $\begin{array}{r}-0.0471^{*} \\
(-2.07)\end{array}$ & \\
\hline crime $1250 \mathrm{~m}$ & & & & & $\begin{array}{r}-0.0225 \\
(-1.30)\end{array}$ \\
\hline _cons & $\begin{array}{r}39.82 \\
(61.08)\end{array}$ & $\begin{array}{r}41.04 \% \\
(12.54)\end{array}$ & $\begin{array}{r}41.23^{*} \\
(9.42)\end{array}$ & $\begin{array}{r}42.39 \% \\
(9.66)\end{array}$ & $\begin{array}{r}41.83^{\text {*n: }} \\
(9.35)\end{array}$ \\
\hline sigma_u² & $\begin{array}{r}41.37^{* *} \\
(13.01)\end{array}$ & $\begin{array}{r}13.83^{*} \\
(10.32)\end{array}$ & $\begin{array}{r}11.10^{\% \mathrm{~m}} \\
(9.57)\end{array}$ & $\begin{array}{r}10.64 \\
(9.40)\end{array}$ & $\begin{array}{r}11.05^{\circ} \\
(9.55)\end{array}$ \\
\hline sigma_e ${ }^{2}$ & $\begin{array}{r}201.35 \% \\
(77.87) \\
\end{array}$ & $\begin{array}{r}161.79^{*} \\
(77.82) \\
\end{array}$ & $\begin{array}{r}161.54^{\circ *} \\
(77.82) \\
\end{array}$ & $\begin{array}{r}161.79^{*} \\
(77.81) \\
\end{array}$ & $\begin{array}{r}161.54 \\
(77.81) \\
\end{array}$ \\
\hline Rho & 0.170 & 0.078 & 0.064 & 0.061 & 0.064 \\
\hline$N$ & 3144 & 3144 & 3144 & 3144 & 3144 \\
\hline
\end{tabular}

Com a inclusão de variáveis, tanto ao nível do aluno quanto ao nível da escola, é pertinente verificar a qualidade de ajustamento do modelo. Quando se acrescentou variáveis ao nível do aluno, o $\mathrm{R}_{1}{ }_{1}$ mostrou que $19,6 \%$ da variância das notas é explicada pelas variáveis desse nível. Já o $\mathrm{R}^{2}{ }_{2}$ mostrou que $66,5 \%$ da variação entre escolas são explicadas por variáveis desse nível. Quando se acrescentou variáveis ao nível da escola e os crimes ocorridos no entrono (crimes $1000 \mathrm{~m}$ ), os valores dos coeficientes de determinação, $\mathrm{R}^{2}{ }_{1}$ e $\mathrm{R}^{2}{ }_{2}$ passaram a ser de $19,6 \%$ e $74,2 \%$, respectivamente. Logo, o poder explicativo do modelo com a inclusão de variáveis ao 
nível do aluno e ao nível da escola aumentou em $10,37 \%$ a capacidade explicativa do efeito-escola (quadro 1). Essas comparaçóes de ajustamento mostram que o modelo tem melhor poder preditivo quando são acrescentados controles aos níveis do aluno e da escola, tendo em vista que isso mede o quanto variáveis de cada nível estáo afetando a variabilidade das notas dos alunos.

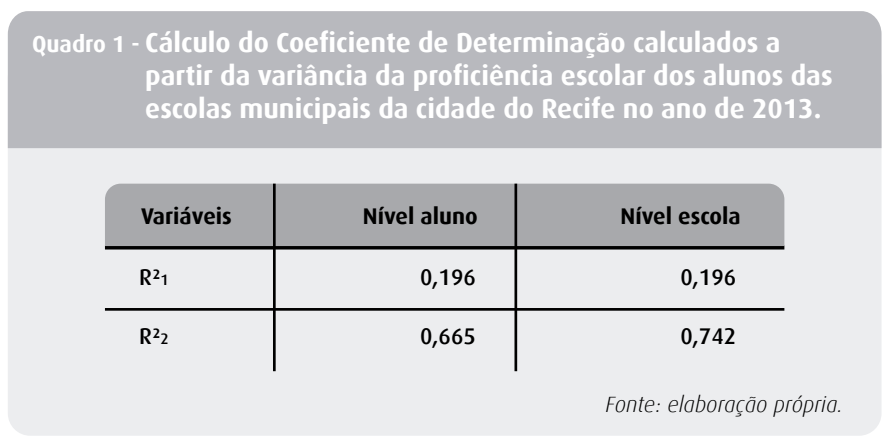

\section{Conclusão}

Este trabalho contribui para a literatura existente ao fazer uso de informaçóes georreferenciadas dos crimes que, por sua vez, permite testar diferentes níveis de agregação destes através da contagem dos homicídios ocorridos em diferentes tamanhos de raios no entorno das escolas. Isso permite que se faça comparaçóes com outros níveis de agregação de dados já que pode existir correlação entre variáveis em um determinado nível de agregação e não haver em outros.

Esta pesquisa mostrou que o desempenho do aluno pode ser influenciado por diversos fatores, incluindo suas características individuais, ambiente familiar e ambiente escolar. $\mathrm{O}$ método de estimação utilizado permitiu ver o impacto que cada nível da estrutura em que o aluno está inserido tem no seu rendimento escolar, uma vez que a modelagem hierárquica permite incorporar a heterogeneidade das escolas.

Utilizando a base de dados com as notas de matemática, as características individuais e familiares dos alunos do $6^{\circ}$ ano das escolas municipais da cidade do Recife, da FUNDAJ, e os dados de homicídios da SDS, foi possível verificar quais variáveis afetam a proficiência escolar dos alunos. Um fator importante na mensuração do impacto da violência nas notas escolares foi utilizar técnicas de georreferenciamento de dados que permitiu analisar a relaçáo dos crimes que ocorreram no entorno das escolas e não nos bairros onde as escolas se localizam. Assim, foi possível testar diferentes raios de distância da ocorrência dos homicídios e verificar quais tiveram correlação com os resultados escolares.

No nível do aluno, a idade do aluno mostrou ter o efeito negativo sobre a proficiência, indicando que alunos repetentes ou que começam a estudar tarde têm um desempenho escolar pior que os demais. A habilidade do aluno, mensurada através de uma prova da mesma disciplina (matemática) no ano anterior, mostrou que alunos que tiveram maiores notas no passado tendem a repetir o resultado no futuro, uma vez que essa variável mostrou efeito positivo na proficiência escolar. 
O ambiente familiar do aluno mostrou ter uma influência positiva nos resultados escolares, uma vez que variáveis como nível de escolaridade do responsável do aluno e se o aluno possui computador em casa tiveram resultados positivos em suas estimativas, ou seja, alunos com pais mais escolarizados e que possibilitam acesso a recursos que facilitam a aprendizagem têm maior proficiência escolar.

O ambiente escolar também tem influência no desempenho do aluno. Nesse estudo, as variáveis de acesso à internet $\mathrm{e}$ a presença de sala para estudo de música mostraram influência positiva e significante sobre o rendimento escolar. A violência dentro da escola náo se mostrou significativa do ponto de vista estatístico, enquanto a violência no entorno, representada pelos homicídios, mostrou um efeito negativo na proficiência escolar. Isso corrobora com a literatura no sentido de que violência no entorno das escolas pode influenciar os resultados escolares (community violence).

A estatística que permitiu verificar o quanto a variaçáa das notas dos alunos, controlando suas características pessoais e familiares, é explicada pelas características da escola foi o coeficiente de correlação intraescolar, onde aproximadamente 6,5\% da variação da proficiência escolar se devem ao efeito-escola.

\section{Referências Bibliográficas}

ALMEIDA, Aléssio Tony Cavalcanti de. Determinantes dos piores e melhores resultados educacionais dos alunos da rede pública de Ensino Fundamental no Brasil. Planejamento e Politicas Publicas, v. 42, 2014, pp. 147-188.
Adaptando-se o coeficiente de correlação, $\mathrm{R}_{2}$, para modelos com dados em estrutura hierárquica, verificou-se que o modelo final se ajusta bem aos dados, uma vez que consegue explicar $74,2 \%$ da variaçáo entre escolas. Já o nível de explicaçáo da variabilidade das notas em relação ao nível do aluno é limitado (da ordem de 19,6\%).

Os resultados sugerem que se investigue outros elementos da escola que possam afetar o desempenho dos alunos, bem como trabalhar com amostras de escolas a nível estadual, federal e/ou privadas com o objetivo de capturar maior heterogeneidade entre as escolas e mensurar de forma mais acurada o efeito-escola sobre o rendimento escolar.

Nesse trabalho, maior parte da heterogeneidade entre escolas acabou se dando pelos seus entornos uma vez que os crimes na vizinhança próxima às escolas se mostraram significantes entre as variáveis que compóem as características de cada escola. Dessa forma, é pertinente pensar em políticas que reduzam a violência próxima ao ambiente escolar para que se possa diminuir a exposiçáo dos jovens a esta e, assim, se evitar os efeitos adversos da associaçáo negativa da violência com seus desempenhos escolares.

ALVES, Maria Teresa Gonzaga; SOARES, José Francisco. 0 efeito das escolas no aprendizado dos alunos: um estudo com dados longitudinais no Ensino Fundamental. Educação e Pesquisa (USP. Impresso), v. 34, 2008, pp. 527-544. 
ARAUJO, Júlia Rocha; SILVEIRA NETO, Raul da Mota. Efeito- Vizinhança E 0 Desempenho Escolar: 0 Caso Dos Estudantes Da Rede Pública De Ensino Da Cidade Do Recife. Anais do XLIV Encontro Nacional de Economia. 2018.

ARAUJO, Fernando; SIQUEIRA, Liedje. Determinantes do desempenho escolar dos alunos da $4^{a}$ série do ensino fundamental no Brasil. Economia e Desenvolvimento, Recife (PE), v. 9, ก. 1, 2010.

ARRUDA, Rodrigo Gomes. 117 f. Três Ensaios sobre Economia da Educação. 2017. Tese (Doutorado) - Universidade Federal de Pernambuco, 2017.

BOWEN, Natasha; BOWEN, Gary. Effects of Crime and Violence in Neighborhoods and Schools on the School Behavior and Performance of Adolescents. Journal of Adolescent Research, v. 14 ก. 3, July 1999, pp. 319-342.

BECKER, Gary. Crime and Punishment: An Economic Approach. Journal of Political Economy, 1968.

BRUECKNER, Jan. Lectures Urban Economics. London: MIT Press Cambridge, 2011.

CONDEPE FIDEM disponível em: <http://www.condepefidem.pe.gov.br/web/condepe-fidem> Acessado em 24/06/2015.

CRUZ, Cláudia Catarina Mendes Silva da. 182f. Modelos Multinível: Fundamentos e Aplicações. Dissertação (Mestrado) - Universidade Aberta, 2010.

DALY, Peter. How large are secondary school effects in Northern Ireland? School effectness and school improvement, v.2, n.4, 1991, pp. 305-323.

FÁVERO, Luiz Paulo et al. Análise de dados. Modelos de regressão com Excel, Stata e SPSS. Rio de Janeiro: Campus Elsevier, 2014.

Métodos Quantitativos com Stata. Rio de Janeiro: Campus Elsevier, 2014.
FERRÃO, Maria Eugênia; FERNANDES, Cristiano. Modelo multinível: Uma aplicação a dados de avaliação educacional. Estudos em Avaliação Educacional, n.22, 2000, pp. .

FERRÃO, Maria Eugênia. Introdução aos modelos de regressão multinível em educação. Campinas: Komedi, 2003.

FERRÃO, Maria Eugênia; BELTRÃO, Kaizô. Tracing schools which do not penalize over age students. 27th Annual Conference of the international association for education assessment. Rio de Janeiro, 2001.

GAMA, Victor Azambuja; SCORZAFAVE, Luiz Guilherme. Os efeitos da criminalidade sobre A proficiência escolar no ensino fundamental no município de São Paulo. Pesquisa e planejamento econômico, v. 43, n. 3, dez. 2013, pp. 447-478.

GUTIERREZ, Gabriela Carrasco. Estimação das escalas dos construtos capital social, capital cultural e capital económico e análise do efeito escola nos dados do Peru-PISA 2000. Tese (Doutorado) - Pontifícia Universidade Católica do Rio de Janeiro, 2005.

HANUSHEK, Eric. The production of education, teacher quality, and efficiency. In: U.S. Office of Education. Do teachers make a difference? Washington, D.C.: Government Printing Office, 1970. pp. 79-99.

MACMILLAN, Ross; HAGAN, John. Violence in the transition to adulthood: adolescent victimization, education, and socioeconomic attainment in later life. Journal of research on adolescence, v. 14, n. 2, 2004, pp. 127-158.

MONTEIRO, Marcela Andreia Salgado P. D. Modelos de regressão multinível: uma aplicação na educação. Dissertação (Mestrado) - Universidade do Minho, 2013.

RIBEIRO, Luiz César Queiroz; KOSLINSKI, Mariane. Fronteiras urbanas da democratização das oportunidades educacionais: o caso do Rio De Janeiro. $3^{\circ}$ Encontro Anual da Anpocs, 2013. 
ROMER, David. Advanced macroeconomics. 3. ed., New York: McGraw-Hill. 2006.

RAUDENBUSH, Stephen; BRYK, Anthony. Hierarchical linear models. 2. ed., CA: Sage Publications, 2002.

SANT'ANNA, Maria Josefina Gabriel, SALATA, André Ricardo. Espaço Urbano e Desigualdade Social: efeito vizinhança e oportunidades educacionais. XIV Congresso Brasileiro de Sociologia, 2009.

SANTOS, Marcelo Justus; KASSOUF, Ana Lúcia. Uma investigação econômica da influência do mercado de drogas ilícitas sobre a criminalidade brasileira. Revista da Anpec, v.8, n.2, 2007, pp.187-2010.
SEABRA, Deborah; SILVEIRA NETO, Raul; MENEZES, Tatiane. Amenidades urbanas e valor das Residências: uma análise empírica para a cidade do Recife. Economia Aplicada, v. 20, п. 1, 2016, pp. 143-169.

SOARES, Tufi Machado. Influência do professor e do ambiente em sala de aula sobre a proficiência alcançada pelos alunos avaliados no simave-2002. Estudos em Avaliação Educacional, v. 28, 2003, pp. 103-123.

TEIXEIRA, Evandro Camargos; KASSOUF, Ana Lúcia. A relação entre violência nas escolas e desempenho escolar no estado de São Paulo em 2007: uma análise multinível. Rede de Economia Aplicada (REAP), 2011. (Working Paper 009). 


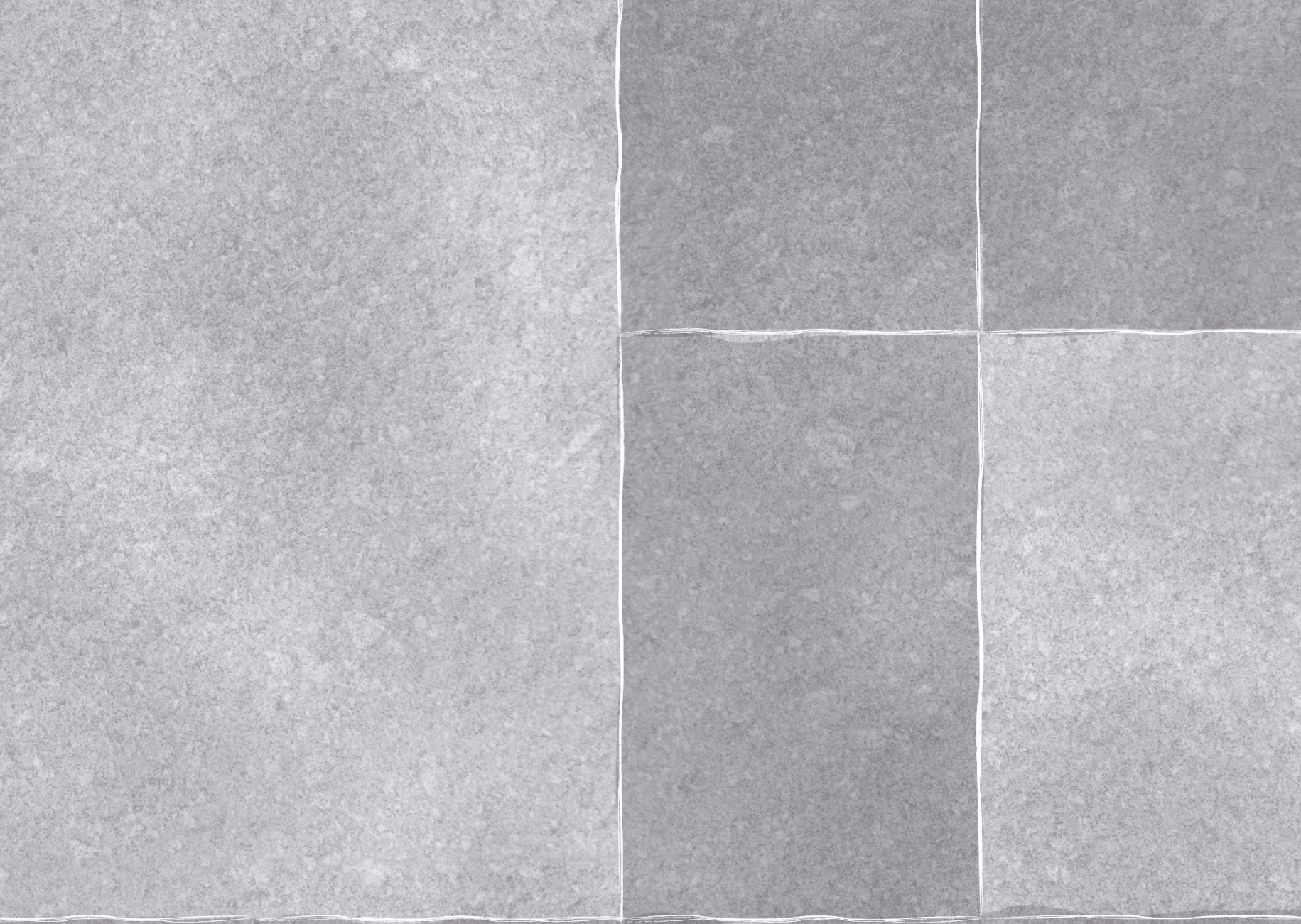

